\title{
IMPACTOS AMBIENTAIS RELACIONADOS A MUDANÇA NA PAISAGEM A PARTIR DA ESPECULAÇÃO IMOBILIÁRIA NO LITORAL NORTE DE MACEIO - AL
}

\author{
Niedja Figueiredo Dantas \\ Professora da Universidade de Pernambuco
}

\begin{abstract}
Resumo - O presente trabalho teve por objetivo analisar como a especulação imobiliária vem impactando o ambiente pelas mudanças interferindo nas configurações da Paisagem do Litoral Norte de Alagoas, especialmente nas comunidades que dependem da pesca nas proximidades da desembocadura do Rio Pratagy, praia da Sereia e Boca do Rio. A análise foi desenvolvida a partir de uma metodologia dialética com confrontação dos discursos dos pescadores e moradores locais e ainda análises de textos de revisão bibliográfica e reportagens dos últimos 3 anos, sobre os impactos ambientais a partir da mudança na paisagem, oriunda da especulação imobiliária nos locais. Foi possível observar que a presença de lideranças locais pertencentes a organizações sociais (Movimento Abrace a Garça, Associações de Moradores do Bairro da Pescaria, Associação de Moradores do Residencial Angra de Ipioca, Pestallozi Parpueira) que contribuíram de modo decisivo para a coesão, a integração e a coordenação de iniciativas relacionadas à valorização e conservação do meio ambiente e discussão sobre a exclusão social. A atuação dessas lideranças requer um conjunto de fatores que contribuam para o fortalecimento e legitimidade ante o conjunto de atores que participam da preservação do meioambiente. Neste sentido, foi observado que a especulação imobiliária na região está relacionada com aspectos econômicos e culturais que se associam para acelerar o acúmulo de resíduos sólidos e ritmo da deterioração dos recursos ambientais.
\end{abstract}

Palavras-chave: Meio Ambiente - Paisagem - Especulação Imobiliária

\section{ENVIRONMENTAL IMPACTS RELATED TO LANDSCAPE CHANGE FROM REAL ESTATE SPECULATION IN THE NORTH COAST OF MACEIÓ - AL}

\begin{abstract}
The objective of this work was to analyze how real estate speculation has impacted the environment by the changes interfering in the landscape configuration of the Northern Coast of Alagoas, especially in the communities that depend on the fishery near the mouth of the Pratagy River, Sereia beach and Boca do Rio The analysis was developed from a dialectical methodology with confrontation of the discourses of fishermen and local residents and also analysis of texts of bibliographical revision and reports of the last 3 years, on the environmental impacts from the change in the landscape, coming from real estate speculation in places. It was possible to observe that the presence of local leaders, belonging to social organizations (movement embraces the Garça, Associations of residents of the fishing district, Association of residents of the residential Angra de Ipioca, PestalloziParpueira) that contributed decisively for cohesion, the integration and coordination of initiatives related to the valorization and conservation of the environment and discussion on social exclusion. The performance of these leaders requires a set of factors that contribute to the strengthening and legitimacy of the set of actors that participate in the preservation of the Environment. In this sense, it was observed that real estate speculation in the region is related to economic and cultural aspects that are associated to accelerate the accumulation of solid waste and the pace of deterioration of environmental resources.
\end{abstract}

Key words: Environment; Landscape; Real Estate Speculation

\section{INTRODUÇÃO}

Estudos têm se preocupado com as concepções de paisagem ao longo do tempo. De acordo com Cullen, paisagem urbana é a arte de tornar coerente e organizado, visualmente, o emaranhado de edifícios, ruas e espaços que constituem o ambiente urbano. Esse conceito de paisagem, elaborado nos anos 1960, exerce forte influência em arquitetos e urbanistas exatamente porque 
possibilita análises sequenciais e dinâmicas da paisagem a partir de premissas estéticas, isto é, quando os elementos e jogos urbanos provocam impactos de ordem emocional (ADAM, 2015).

Segundo Resende (2013), no espaço urbano as sociedades deixam impressas suas marcas, suas obras e as contradições que permeiam a existência humana, onde as cidades com suas diversas formas espaciais e conteúdos expressam em última instância a materialização de relações sociais que são condição e meio indispensáveis para a reprodução de toda a dinâmica social.

Para Rogers (2008), a capacidade das cidades está sendo solicitada até o limite de sua expansão e esse índice de padrões tradicionais de acomodação do crescimento urbano tornaram-se obsoletos. A migração das pessoas e atividades dos centros urbanos tradicionais para bairros residenciais distantes causa a aceleração do desenvolvimento dos subúrbios e, consequentemente, a saturação da infraestrutura urbana, além de aumentar a geração de resíduos, o uso de automóveis (congestionamento), a poluição do ar e da água e a degradação de áreas florestais.

Aspectos econômicos e culturais se associam à questão demográfica para acelerar o ritmo da deterioração dos recursos ambientais. A quantidade de resíduos sólidos produzidos pelas populações guarda relação não só com o nível de riqueza, refletido na capacidade econômica para consumir, mas também com os valores e hábitos de vida, determinantes do grau de disposição para a realização do consumo. (GODECKE et al., 2012.)

A globalização da economia tem promovido uma mudança nas formas de organização produtiva. A expansão das empresas em unidades produtivas instaladas em vários países do mundo, especialmente onde oferecem baixos salários e incentivos fiscais, mesmo por tempo determinados, afirma a falência do modelo de produção fordista ao mesmo tempo em que consolida a chamada "especialização flexível". Neste contexto neoliberal que se fundamenta um Estado mínimo, privatizações e um modelo de desenvolvimento econômico que tem como base juros altos e atração de capital estrangeiro para ganhos de juros. Assim, no contexto de especulação imobiliária as construtoras implantam empreendimentos e estabelecem padrões que conseguem influenciar ou provocar revisões em um Plano Diretor de um determinado município, a partir de um discurso "de modernidade necessária e inevitável”.

O processo de urbanização traz consequências desfavoráveis ao meio ambiente, como a falta de tratamento e disposição adequados para os efluentes e resíduos sólidos urbanos, distribuição de áreas de afluência de lençóis freáticos, indisponibilidade de água tratada e serviços de esgoto para os moradores (SANTOS e CHAVES, 2012).

Para evitar a degradação ambiental em áreas urbanas Silva et al (2013), comentam que se faz necessário acompanhar o desenvolvimento local e indicar possíveis falhas no planejamento e gestão de obras na área a ser trabalhada e dos recursos voltados e apresentados por ela. Dessa 
forma, afirmam que se pode racionalizar a exploração dos bens disponíveis e direcionar a ocupação do solo para, em função de sua capacidade de exploração, empregando-se meios de preservar a qualidade do ambiente.

A implementação de um Plano Diretor requer considerar as especificidades de cada município. O reconhecimento de que cada território possui características e especificidades distintas, assim como os atores locais possuem comportamentosme requerimentos particulares, os quais vão apontar para soluções também específicas para seu atendimento efetivo é crucial para a formulação e a implementação do Código de Urbanismo e Edificações, bem como, na busca da participação da sociedade.

Na década de 1990 e nos anos 2000 inúmeros hotéis e resorts foram implantados nos Bairros de Pajuçara, Ponta Verde e Jatiúca, após a instalação destes nestes bairros, a rede hoteleira, assim como também a construção civil, migrou em direção ao litoral Norte de Maceió, com projetos de construção de altos edifícios residenciais com mais de 20 andares muito próximos a praia, causando modificações e novas configurações na paisagem destes bairros, impactos no meio ambiente, nos riachos, córregos e manguezais desta região e com impactos também sobre a população local. Neste sentido, este estudo pode contribuir também para a discussão de novos Planos Diretores, bem como repensar o Planejamento Urbano do Litoral Norte de Maceió e a discussão de ações de Preservação e conservação do Meio Ambiente.

A Área de Proteção Ambiental (APA) do Pratagy é uma Unidade de Conservação (UC) instituída pela Lei Estadual no 37.589/1998, tem área 13.369,5 hectares e abrangem os municípios de Messias, Rio Largo e Maceió. Essa APA foi criada com o objetivo de harmonização das atividades com o equilíbrio ambiental do ecossistema Bacia Hidrográfica do Rio Pratagy.

Segundo Lei no 9.985/2000 que institui o Sistema Nacional de Unidades de Conservação (SNUC), as Áreas de Proteção Ambiental estão nos grupos das unidades de conservação de uso sustentável, cujo objetivo é compatibilizar a conservação da natureza com o uso sustentável de parcela dos seus recursos naturais. De acordo com o Art. 15 da supracitada Lei, APA é uma área em geral extensa, com um certo grau de ocupação humana, dotada de atributos abióticos, bióticos, estéticos ou culturais especialmente importantes para a qualidade de vida e o bem-estar das populações humanas, e tem como objetivos básicos proteger a diversidade biológica, disciplinar o processo de ocupação e assegurar a sustentabilidade do uso dos recursos naturais.

De acordo com o IMA (Instituto de Meio Ambiente do Estado de Alagoas) um dos principais problemas da APA do Pratagy é a ausência da mata ciliar que foi substituída pela monocultura da cana-de-açúcar, porém ainda é possível encontrar área preservadas de Mata Atlântica nas bordas dos tabuleiros e manguezal próximo à foz do Rio Pratagy. Um outro efeito negativo na APA é a 
ocupação urbana desordenada, por povoados ribeirinhos que se instalam às margens do rio.

Neste sentido, o objetivo desta pesquisa foi analisar como a especulação imobiliária e as novas Configurações da Paisagem no Litoral Norte de Alagoas promoveram impactos no Meio Ambiente.

\section{METODOLOGIA}

Para avaliar como a especulação imobiliária vem interferindo nas conformações paisagísticas do Litoral Norte de Alagoas, foram desenvolvidas análises referentes as regiões da APA do Pratagy (especialmente nas comunidades tradicionais que dependem da pesca) nas proximidades da desembocadura do Rio Pratagy e praia da Sereia, assim como no povoado Boca do Rio e Pescaria e no residencial Angra de Ipioca e Sauaçuhi, onde houve um desvio no curso da vegetação de mangue para facilitar a construção de loteamentos.

O interesse nas questões que incidem na problemática da modificação das paisagens, impactos ambientes e na inclusão ou exclusão da população local neste processo permearam a pesquisa, que foi desenvolvida utilizando como ferramenta de avaliação pesquisas bibliográficas, documentais e pesquisa de campo.

A análise das entrevistas foi desenvolvida a partir de uma metodologia dialética a partir da confrontação dos discursos de 10 pescadores e 15 moradores locais dos bairros do Litoral Norte de Maceió (Figura 1) (Bairros de Cruz das Almas, Guaxuma, Garça Torta, Praia da Sereia, Riacho Doce e Ipioca), 2 técnicos da SMCCU (Secretaria de Convívio Urbano da Prefeitura de Maceió) e 3 gerentes/ proprietários de Construtoras com Empreendimentos no Litoral Norte de Maceió - AL, totalizando uma amostra total de 20 pessoas, distribuída em 4 grupos (Grupo I - pescadores; Grupo 2 - moradores dos bairros do litoral Norte de Maceió; Grupo 3 - técnicos da SMCCU; e Grupo 4 - gerentes de Construtoras com propostas de empreendimentos no litoral Norte de Maceió). As entrevistas foram realizadas no período entre fevereiro a julho de 2017, a partir de roteiro previamente elaborado, a fim de identificar as concepções de turismo sustentável, as iniciativas dos moradores (entre elas o movimento "abrace a garça", os projetos elaborados e efetivamente desenvolvidos, as dificuldades enfrentadas e os principais entraves para o desenvolvimento local a partir da análise dos dados coletados nas entrevistas com pescadores e moradores dos bairros acima especificados sobre a especulação imobiliária na região e seus impactos no meio ambiente.

A pesquisa documental foi desenvolvida sobre os documentos do IMA (Instituto de Meio Ambiente), Museu da Imagem e do Som (MISA), na busca e captura de imagens do Litoral Norte de Maceió e sua evolução ao longo dos últimos 53 anos. O interesse nas questões que incidem na problemática da modificação da paisagem com o desmatamento de vegetação de mangue, causando 
impactos ambientes irreversíveis, inclusive o aumento do nível do mar no litoral norte de Maceió.

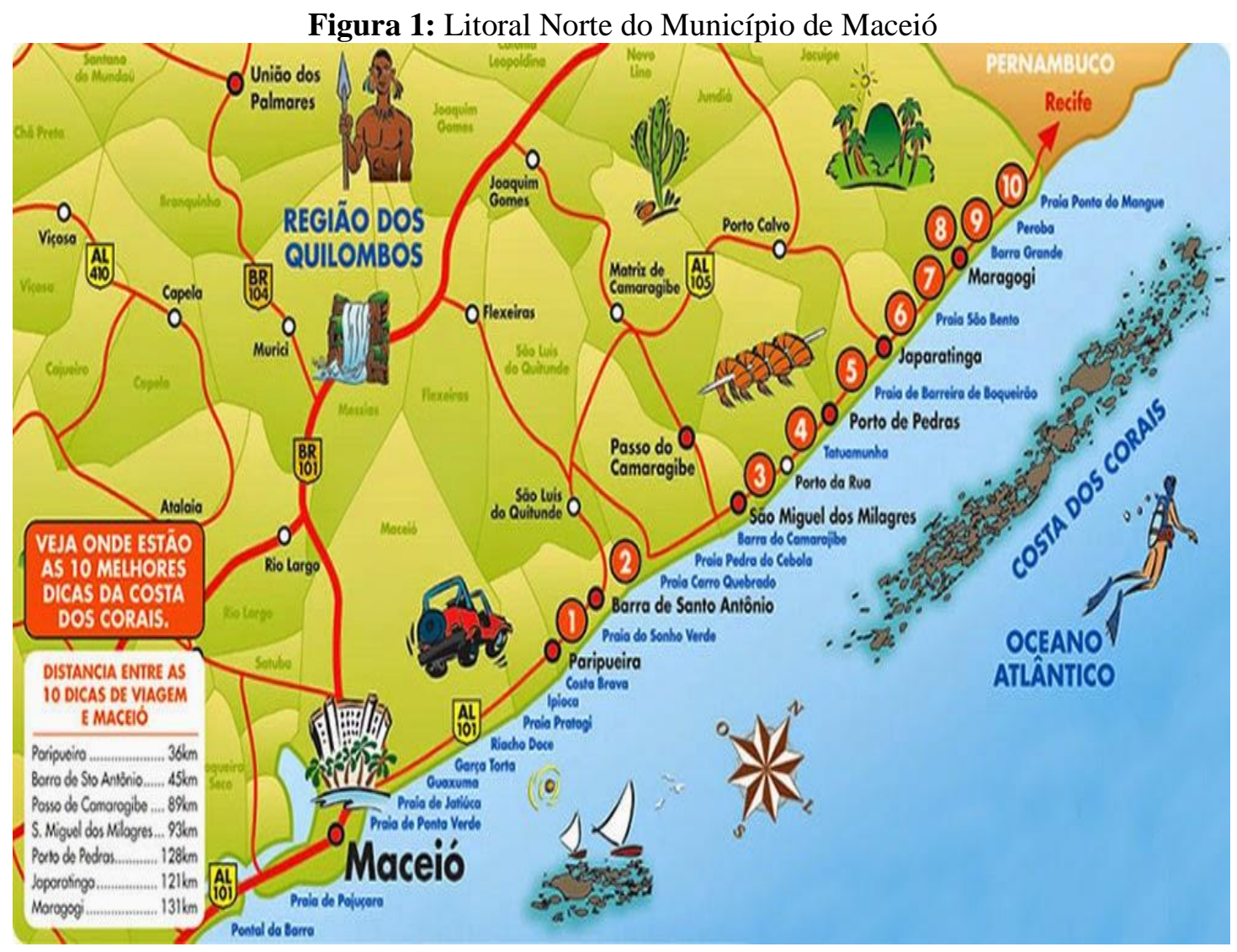

Fonte: http://mapasblog.blogspot.com.br/2014/09/mapas-do-litoral-norte-de-alagoas.html

\section{DISCUSSÃO DOS RESULTADOS}

De acordo com as entrevistas realizadas com moradores dos bairros Cruz das Almas, Guaxuma, Garça Torta, Riacho Doce e Ipioca e pescadores, foi identificada a importância de lideranças locais no papel de agregar atores e iniciativas para ações nestes bairros estudados. $\mathrm{O}$ único bairro em que foi verificado a presença de Movimentos a favor da defesa do Meio Ambiente, foi no Bairro de Garça Torta, com o movimento "Abrace a Garça” (movimento dos moradores do bairro Garça Torta voltado para a preservação do meio ambiente neste bairro e contra a especulação imobiliária, sobretudo também contra a construção de prédios altos, acima de 3 andares). A presença de indivíduos que atuem como lideranças locais, pertencentes a organizações sociais contribui de modo decisivo para a coesão, a integração e a coordenação das iniciativas relacionadas a valorização e conservação do Meio Ambiente.

O Plano Diretor de um Município pode gerar condições que podem estimular ou desestimular o desenvolvimento sócioeconômico de uma região, estimular ou não o turismo, provocar impacto no meio ambiente ou impedir que a dinâmica do ecossistema seja continuada, 
de acordo com os preceitos e diretrizes que estão vislumbrados neste instrumento.

Portanto, um aspecto importante a ser considerado na elaboração de um plano diretor é a participação da sociedade. Atualmente, há uma reinterpretação do significado do "público" implicando a participação de outros atores, além do governo, na elaboração, inserção e avaliação das políticas públicas. Nos vários níveis em que possa ocorrer a implementação de um plano diretor, diversos agentes devem ser considerados: Órgãos de Financiamento: BNDES; BID e outros; Órgãos de Suporte: IMA (Instituto do Meio Ambiente), Universidades, Institutos de Pesquisa; Grupos de Interesse: Ambientalistas; ONGs; Órgãos Públicos Governamentais; Agentes Financeiros; População local e outros afins.

Com relação aos textos das reportagens analisadas, foram observados alguns trechos importantes que retratam a especulação imobiliária e o impacto nos resíduos sólidos no litoral Norte de Maceió. Dentre outros, pode-se citar: “A presença desses edifícios com 4 apartamentos por andar, aumentará em 65\% o número de domicílios do bairro, no qual $98 \%$ dos dejetos sanitários vão para fossas sépticas e fossas rústicas e 50\% da água potável obtida por poços particulares. " (Fonte: Jornal eletrônico Repórter Alagoas. Reportagem do 15/12/2014 "Resistir ao saque do Litoral Norte de Maceió").

Atualmente, a rodovia AL-101 Norte está sendo duplicada e nesta localidade há placas anunciando a construção de 3 torres residenciais com 27 andares na praia de Garça Torta. Os poços e as fossas encontram-se tocando o mesmo lençol freático, um grave risco de contaminação. Não estão planejados construção de redes de esgoto e reforços dos já deficientes sistemas de energia, transporte público e comunicação. E a especulação imobiliária é apresentada na propaganda das construtoras e nos discursos de prefeitos e vereadores como a modernidade possível e desejada. De fato, os impactos ao meio ambiente não aparecem nos discursos dos técnicos da Secretaria de Convívio Urbano da Prefeitura de Maceió (SMCC) e dos empresários donos de construtoras, o que se verifica que a preservação de mangues, rios e APA's não chegam a ser tão importante quanto os ganhos promovidos "pelo grande capital" para alguns.

O Plano Diretor do Município de Maceió em vigor se constitui na Lei 5.593, de 08 de fevereiro de 2007, no Código de Urbanismo e Edificações de Maceió, a partir dos objetivos que se deseja para o Município, a partir de uma discussão democrática.

O discurso do desenvolvimento social sustentável reforça o turismo como potencial gerador de emprego e renda e promotor da redução da desigualdade social. Neste momento também se inicia a preocupação com a preservação dos recursos naturais justamente como elemento central da preocupação com o meio ambiente.

"Através do estabelecimento de princípios, diretrizes e normas, o plano deve fornecer 
orientações para as ações que, de alguma maneira, influenciam no desenvolvimento urbano. Essas ações podem ser desde a abertura de uma nova avenida, até a construção de uma nova residência, ou a implantação de uma estação de tratamento de esgoto, ou a reurbanização de uma favela. Essas ações, no seu conjunto, definem o desenvolvimento da cidade, portanto é necessário que elas sejam orientadas segundo uma estratégia mais ampla, para que todas possam trabalhar (na medida do possível) em conjunto na direção dos objetivos estabelecidos em consenso." (SABOYA, 2016).

De acordo com Nascimento (2016), faz-se necessário garantir a preservação do meio ambiente através de leis e estratégias que envolvessem a sua conservação, já que é de suma importância que as comunidades encontrem formas para viver de forma mais harmônica. A existência do amparo legal é de grande importância para conservação e proteção do ambiente.

O pensar sobre a especulação imobiliária no Litoral Norte de Alagoas nos conduz a várias reflexões, entre elas: Construção de prédios em terrenos de marinha; Impactos ambientais; quem lucra com a especulação imobiliária?

Haddad citando Boiser (2014) afirma que o processo de desenvolvimento de uma região, que pressupõe o seu crescimento econômico dependerá, fundamentalmente, da sua capacidade de organização social e política, que se associa ao aumento da autonomia regional para a tomada de decisões, ao aumento da capacidade para reter e reinvestir o excedente econômico gerado pelo seu processo de crescimento regional, a um crescente processo de inclusão social, a um processo permanente de conservação e preservação do ecossistema regional.

Essa capacidade de organização social da região é o fator endógeno por excelência para transformar o crescimento em desenvolvimento, através de uma complexa malha de instituições e de agentes de desenvolvimento, articulados por uma cultura regional e por um projeto político regional (BOISIER, 2014). Ainda segundo o mesmo autor, o desenvolvimento de uma região ou localidade, no longo prazo, depende profundamente da sua capacidade de organização social e política para modelar o seu próprio futuro (processo de desenvolvimento endógeno), o que se relaciona, em última instância, com a disponibilidade de diferentes formas de capitais intangíveis na região ou localidade.

Para Rogers (2008) “as cidades devem ser vistas como sistemas ecológicos” em que é preciso planejamento e gerenciamento do uso de seus recursos, através de uma nova forma de planejamento urbano holístico e abrangente. Planejar uma cidade sustentável exige uma ampla compreensão das relações entre: cidadãos, serviços, políticas de transporte e geração de energia; além do conhecimento do impacto total no meio ambiente local e numa esfera geográfica mais ampla. $\mathrm{O}$ autor defende que cidades densas e um planejamento integrado são mais eficientes energeticamente e consomem menos recursos ambientais, além de evitar a expansão urbana sobre áreas rurais. 
Para Santos et al. (2015) o adensamento populacional aumenta a concentração de resíduos que necessitam de maior empenho por parte do Poder Público na coleta, transporte e na disposição final dos resíduos sólidos urbanos. Outro fator decorrente do processo de verticalização é o aumento da carga de esgotos que precisa receber tratamento adequado antes de ser liberada nos copos hídricos. Portanto, percebe-se que o processo de verticalização das cidades engloba uma série de impactos de ordem social, econômica, política e, sobretudo, ambiental. Os problemas ambientais decorrentes da verticalização afetam toda a dinâmica de uma sociedade, pois vão desde a supressão da vegetação, compactação e impermeabilização do solo, aumento de temperatura local e, até mesmo podendo ocasionar problemas psicológicos.

Considerando-se capitais intangíveis como o clima de relações interinstitucionais (cooperação, conflito, seu grau de modernidade), o estoque de conhecimentos e habilidades que possuem os indivíduos que residem na região e sua capacidade para exercitá-los; a tradução de práticas de políticas democráticas, de confiança nas instituições, de preocupação pessoal com os assuntos políticos, de associatividade entre as esferas públicas e privadas; cooperação na formação de novos grupos ou em realizar ações em comum; capacidade real ou latente de toda a comunidade para articular de forma democrática as diversas formas de capital intangível disponíveis nessa comunidade (BOISIER, 2014).

Assim, um processo de desenvolvimento endógeno é concebido e implementado a partir da capacidade que dispõe determinada comunidade para a mobilização social e política de recursos humanos, materiais e institucionais, em uma determinada localidade ou região.

Neste sentido, não se pode esperar que a promoção do desenvolvimento econômico e social das regiões e dos municípios do Estado de Alagoas ou especificamente no Município de Maceió venha a ser promovida apenas indústria da construção civil, a qual, na verdade, tem sido comprovadamente poluente, construído grandes espigões em terreno de marinha e sem se preocupar com a infraestrutura de esgoto da região.

Para Sen (2013), uma concepção adequada de desenvolvimento deve ir muito além de variáveis relacionadas à renda. $\mathrm{O}$ desenvolvimento deve estar relacionado, principalmente, com a melhoria da vida que se leva e daliberdade que se desfruta. É fator incontestável na sociedade pós-industrial a preocupação com a implantação de modelos de desenvolvimento social que diminua grande "gap" existente entre ricos e pobres.

Esta análise nos leva as seguintes questões: Como acontece o envolvimento da comunidade local? A comunidade é consultada? É convidada a participar?

Neste contexto pode se discutir que a especulação imobiliária no litoral Norte do Município de Maceió não tem se mostrado includente. O aspecto mais importante na proposta 
da sustentabilidade social é a participação social. Sendo esta um indicador de liberdades democráticas, de equidades nas decisões, e também um elemento decisivo na potencialização dos esforços produtivos. As entrevistas mostraram que os moradores entrevistados não participaram da construção e desconhecem a divulgação do Plano Diretor da Cidade de Maceió.

Um dos aspectos interessantes na discussão sobre a participação dos diversos atores, que emerge no bojo da iniciativa de integração de ações é a articulação dos atores, e no caso da discussão a respeito dos impactos ambientais das novas construções e novas configurações na paisagem urbana do litoral norte de Maceió não aconteceu, os moradores do lugar não foram partícipes das mudanças ocorridas, só participaram os donos de construtoras, prefeitura de Maceió e IMA.

\section{CONCLUSÕES}

Foi observado que a ação das lideranças comunitárias do Litoral Norte de Maceió têm lutado através de movimentos sociais e de associação de moradorescom ações que favoreçam seu fortalecimento da preservação do Meio Ambiente, percebe se que são ações ainda embrionárias mas contudo conseguem atrair e chamar atenção da imprensa local para a necessidade de se repensar as questões ambientais, entre elas a limitação do gabarito para a construção de prédios, com limitação do número de andares, bem como em relação a coleta de lixo reciclável e conservação da vegetação do mangue no litoral norte de Maceió.

Desta forma, sugere-se que sejam desenvolvidas atividades no âmbito da educação ambiental nos bairros circunvizinhos a APA do Pratagy para que os atores sociais que ali vivem, aflorem o sentimento de pertencimento que as riquezas naturais que os cercam é um patrimônio de todos. Essas ações podem ser veiculadas a partir de campanhas de cunho continuado, que intentem a mobilização e sensibilização dos moradores ecomunidades para as questões ambientais.

O estudo permitiu observar que a especulação imobiliária tem promovido novas Conformações da Paisagem no Litoral Norte de Alagoas, com a aprovação de condomínios e loteamentos residenciais, com ausência de atividades sustentáveis que afetam diretamente as comunidades analisadas, especialmente na APA do Pratagy, sendo este estudode relevância social e ambiental.

\section{REFERÊNCIAS}

ADAM, Roberto Sabatella. 2008. Revista Eletrônica da Vinci, Curitiba, v. 5, n. 1, p. 61-68, 2015. ANALISANDO O CONCEITO DE PAISAGEM URBANA DE GORDON CULLEN. http://www.up.edu.br/davinci/5/pdf21.pdfAcesso em 29.03.2016.

BOISIER, Sérgio. Desenvolvimento Regional e Urbano. Rio de Janeiro: IPEA, 2014.

BRASIL. SNUC - Sistema Nacional de Unidades de Conservação. Lei Federal Nº 9.985, de 18 de 
Julho de 2000.

BRASIL. Estatuto da Cidade: guia para implementação pelos municípios e cidadãos. 2 ed. Brasília: Câmara dos Deputados, Coordenação de Publicações, 2002.

GODECKE, M, V.; NAIME, R. H.; FIGUEREDO, J. A. S. O Consumismo e a Geração de Resíduos Sólidos Urbanos No Brasil. Revista Eletrônica em Gestão, Educação e Tecnologia Ambiental. v.8, nº 8, p. 1700-1712, 2012.

IMA/AL - Instituto de Meio Ambiente de Alagoas. Disponível em: http://www.ima.al.gov.br/unidadesde-conservacao/uso-sustentavel/apa-do-pratagy/

LESSA, Golbery. Jornal eletrônico Repórter Alagoas. Reportagem do 15/12/2014 "Resistir ao saque do Litoral Norte de Maceió". http://reporteralagoas.com.br/novo/resistir-ao-saque-do-litoral-norte-demaceio/ Acesso em 29.03.2016

NASCIMENTO, D. da S. Alterações sociais, econômicas e ambientais da Penha-PB de correntes do processo de urbanização. João Pessoa/PB, 2016. 54p.

NBR 12267 - Normas para elaboração de plano diretor. ABNT - Associação Brasileira de Normas Técnicas, 1990.

RESENDE, U. P. Especulação imobiliária e verticalização urbana: um estudo a partir do Parque Municipal Cascavel em Goiânia. Geografia (Londrina), v.22, n.2. p. 79-102, maio/ago. 2013

ROGERS, Richard. Cidades para um pequeno planeta. 1. ed. Barcelona: Gustavo Gili, 2008.

SABOYA, Renato. Concepção de um sistema de suporte à elaboração de planos diretores participativos. 2007. Tese de Doutorado apresentada ao Curso de Pós-Graduação em Engenharia Civil - Universidade Federal de Santa Catarina. http://urbanidades.arq.br/2008/06/o-que-e-plano-diretor/ Acesso em 29.03.2016.

SANTOS, Leilson Alves dos; SILVA, Denise de Brito; SOUSA, Tiago Bruno de; FORTES, Ana Carolina Chaves; VIANA, Bartira Araújo da Silva. VI Congresso Brasileiro de Gestão Ambiental Porto Alegre. 2015 Impactos socioambientais resultados do processo de verticalização.

SANTOS, F.O.; CHAVES, M. R. Evolução urbana, especulação imobiliária e fragilidade ambiental em Caldas Novas (GO). Caminhos de Geografia. Uberlândia v. 10, n. 32 p. 126 - 137, dez/2012.

SEN, Amartya. Desenvolvimento como Liberdade. São Paulo: Cia das Letras, 2013.

SILVA, Cláudia \& CALLAPEZ, Pedro. Estratégias e atividades no ensino da Geologia: a importância das aulas de campo em práticas pedagógicas relativas à sedimentogénese e ao ambiente sedimentar. ColeçãoCiências da Terra, número especial, 2016. 